Article

\title{
Epidemiology of SARS-CoV-2 Infection in Italy Using Real-World Data: Methodology and Cohort Description of the Second Phase of Web-Based EPICOVID19 Study
}

\author{
Fulvio Adorni ${ }^{1} * \mathbb{D}^{\mathbb{D}}$, Nithiya Jesuthasan ${ }^{1} \mathbb{D}$, Elena Perdixi ${ }^{1}$, Aleksandra Sojic ${ }^{1}\left(\mathbb{D}\right.$, Andrea Giacomelli ${ }^{2} \mathbb{D}$, \\ Marianna Noale $^{3}\left(\mathbb{D}\right.$, Caterina Trevisan ${ }^{4,5}(\mathbb{D})$, Michela Franchini ${ }^{6}(\mathbb{D})$, Stefania Pieroni ${ }^{6}\left(\mathbb{D}\right.$, Liliana Cori ${ }^{6}(\mathbb{D})$

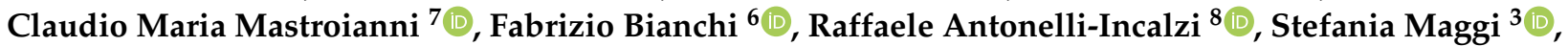 \\ Massimo Galli $^{2}$, Federica Prinelli ${ }^{1}$ iD and on behalf of the EPICOVID19 Working Group ${ }^{\dagger}$
}

check for updates

Citation: Adorni, F.; Jesuthasan, N.; Perdixi, E.; Sojic, A.; Giacomelli, A.; Noale, M.; Trevisan, C.; Franchini, M.;

Pieroni, S.; Cori, L.; et al.

Epidemiology of SARS-CoV-2 Infection in Italy Using Real-World Data: Methodology and Cohort Description of the Second Phase of Web-Based EPICOVID19 Study. Int. J. Environ. Res. Public Health 2022, 19, 1274. https://doi.org/10.3390/ ijerph19031274

Academic Editor: Beatrice Casini

Received: 27 December 2021

Accepted: 19 January 2022

Published: 24 January 2022

Publisher's Note: MDPI stays neutral with regard to jurisdictional claims in published maps and institutional affiliations.

Copyright: (C) 2022 by the authors. Licensee MDPI, Basel, Switzerland. This article is an open access article distributed under the terms and conditions of the Creative Commons Attribution (CC BY) license (https:// creativecommons.org/licenses/by/ $4.0 /)$.
1 National Research Council, Institute of Biomedical Technologies, Via Fratelli Cervi 93, 20054 Segrate, Italy; nithiya.jesuthasan@itb.cnr.it (N.J.); elenaperdixi@gmail.com (E.P.); aleksandra.sojic@itb.cnr.it (A.S.); federica.prinelli@itb.cnr.it (F.P.)

2 Infectious Diseases Unit, Department of Biomedical and Clinical Sciences L. Sacco, Università di Milano, ASST Fatebenefratelli Sacco, 20157 Milan, Italy; dott.giacomelli@gmail.com (A.G.); massimo.galli@unimi.it (M.G.)

3 National Research Council, Neuroscience Institute, Aging Branch, Via Vincenzo Maria Gallucci 16, 35128 Padova, Italy; marianna.noale@in.cnr.it (M.N.); stefania.maggi@in.cnr.it (S.M.)

4 Geriatric Unit, Department of Medicine (DIMED), University of Padova, Via Giustiniani 2, 35128 Padova, Italy; caterina.trevisan.5@studenti.unipd.it

5 Department of Medical Sciences, University of Ferrara, Via Aldo Moro 8, Cona, 44124 Ferrara, Italy

6 National Research Council, Institute of Clinical Physiology, Via G. Moruzzi 1, 56124 Pisa, Italy; michela.franchini@ifc.cnr.it (M.F.); stefania.pieroni@ifc.cnr.it (S.P.); liliana.cori@ifc.cnr.it (L.C.); fabriepi@ifc.cnr.it (F.B.)

7 Department of Public Health and Infectious Diseases, Sapienza University of Rome, 00185 Rome, Italy; claudio.mastroianni@uniroma1.it

8 Unit of Geriatrics, Department of Medicine, Biomedical Campus of Rome, 00128 Rome, Italy; r.antonelli@unicampus.it

* Correspondence: fulvio.adorni@itb.cnr.it

+ Membership of the EPICOVID19 Working Group is provided in the Supplementary Material, epicovid19@itb.cnr.it.

Abstract: Digital technologies have been extensively employed in response to the SARS-CoV-2 pandemic worldwide. This study describes the methodology of the two-phase internet-based EPICOVID19 survey, and the characteristics of the adult volunteer respondents who lived in Italy during the first (April-May 2020) and the second wave (January-February 2021) of the epidemic. Validated scales and ad hoc questionnaires were used to collect socio-demographic, medical and behavioural characteristics, as well as information on COVID-19. Among those who provided email addresses during phase I (105,355), 41,473 participated in phase II (mean age 50.7 years \pm 13.5 SD, 60.6\% females). After a median follow-up of ten months, $52.8 \%$ had undergone nasopharyngeal swab (NPS) testing and $13.2 \%$ had a positive result. More than $40 \%$ had undergone serological test (ST) and $11.9 \%$ were positive. Out of the 2073 participants with at least one positive ST, 72.8\% had only negative results from NPS or never performed it. These results indicate that a large fraction of individuals remained undiagnosed, possibly contributing to the spread of the virus in the community. Participatory online surveys offer a unique opportunity to collect relevant data at individual level from large samples during confinement.

Keywords: SARS-CoV-2; COVID-19; testing; observational study; web-based survey; self-reported data; public health 


\section{Introduction}

The coronavirus disease 2019 (COVID-19) caused by the severe acute respiratory syndrome coronavirus-2 (SARS-CoV-2), has posed an unprecedented public health emergency worldwide [1]. From the disease outbreak in February 2020 to 20 December 2021, with $5,389,155$ confirmed cases and 135,641 deaths, Italy was the first Western country to be severely affected by the COVID-19 pandemic [2].

During the first wave of the pandemic peak worldwide, epidemiological surveillance strategies were mainly based on the testing of symptomatic patients with serious diseases requiring hospitalization and intensive medical care $[3,4]$. Despite efforts to ensure universal access to molecular testing, the massive spread of the infection has de facto restricted the diagnosis of COVID-19 only to infected people who exhibited severe symptoms. This limitation, combined with the lack of official standards in the detection and diagnosis of asymptomatic or pauci-symptomatic patients, heavily affected the effectiveness of testing strategies and contact tracing, which in turn compromised the control of the spread of SARS-CoV-2 in the community [5]. As a result of the limited availability of populationbased data, the inconsistency between official statistics of different countries has made a global comparison difficult [6].

To easily and freely collect real-time and population-based data, multiple eHealth technologies have been employed [7]. In several countries, such as the UK [8], US [9], Israel [10], and Canada [11,12], large numbers of participants were recruited via mobile applications and web-based tools, to collect information on symptoms, psychosocial determinants, behavioural changes; to monitor positive cases; and in some circumstances to carry out contact tracing.

The results of participatory surveillance platforms have contributed to increasing knowledge of the characteristics of SARS-CoV-2 infection and associated factors at the population level, especially in areas with insufficient testing capacity. Typical symptom patterns like anosmia, dysgeusia, fever, shortness of breath, and cough were consistently observed in association with the self-reported positive SARS-CoV-2 test, highlighting the relevance of collaborative syndromic surveillance during pandemic waves worldwide [13]. Furthermore, digital epidemiological surveillance has filled the gaps due to the lack of seroprevalence studies, attempting to size up more completely the real, yet unknown, spread of the epidemic.

In response to the COVID-19 pandemic and to the lack of Italian epidemiological data on persons who experienced the mild-to-severe disease in the general population, a large sample of more than 198,000 voluntary adults who lived in Italy during the first lockdown was recruited through a web-based approach. These data allowed to better understand the association of symptoms (or cluster of symptoms) [14-16] and smoking habits [17] with COVID-19, the role of vaccination for other vaccine-preventable diseases [18,19], as well as to characterize psychological aspects of the population [20] and health policy issues [21] in the context of the pandemic. During the second wave of the epidemic in Italy, a follow-up questionnaire was sent by e-mail to collect further data on SARS-CoV-2 testing, COVID-19 related symptoms, hospitalization, and behavioural and psychosocial factors associated with the pandemic. This article describes the rationale, methodology, and socio-demographic and clinical characteristics of people who participated in the second phase of the internet-based EPICOVID19 study in Italy, in January-February 2021.

\section{Materials and Methods}

\subsection{Development of the EPICOVID19 Questionnaires}

EPICOVID19 is an Italian national internet-based survey with a cross-sectional research design in phase I [14] and a longitudinal design in phase II, carried out on a self-selected sample of adult volunteers (18+ years old) living in Italy during the first and second waves of the pandemic. Study design and data were registered in ClinicalTrials.gov (https: / / clinicaltrials.gov / ct2/show / NCT04471701, accessed on 18 December 2021). The EPICOVID19 study was established as a collaborative project of a working group includ- 
ing epidemiologists, physicians with expertise in infectious diseases, biostatisticians, and public health professionals, with the aim of improving knowledge about SARS-CoV-2 infection. The EPICOVID19 survey was designed after a comprehensive literature review of existing research as to ensure maximal harmonization and comparability with other large population studies. Most of the items in the questionnaire were chosen based on standardized, validated scales. We checked the clarity of the items before launching the questionnaire to the general population in order to avoid as much as possible misunderstandings in the questions and answers and refine readability. With this aim and for both phase I and phase II, we asked a group of 20 volunteers from outside the working team, chosen by convenience, aged between 18 and 70 years, sex-balanced, and with different levels of education, to fill out the questionnaire and to provide us with their feedback on its compilation. Following the feedback received, we finalized the questionnaires after adjusting the question flow and improving the simplicity of the language.

\subsection{Content of the EPICOVID19 Questionnaire}

Participants were asked to complete the two questionnaires (phase I and II) after reading an introductory page (which briefly described the rationale and objectives of the study and the scientific consortium), and after accepting the option to provide consent to participate. The content of the first questionnaire was described in a previous publication [14]. The phase II questionnaire is included in Annex 1, and a comparison of its content with the one of phase I is presented in Table S1. The validated scales and questionnaires used in the two surveys are described in Table S2.

\subsection{Sample Recruitment and Study Population}

The two-wave web-based surveys were implemented using the European Commission's official open-source management tool EUSurvey (https: / / ec.europa.eu/eusurvey, accessed on 18 December 2021). The link to the first questionnaire was shared since 13 April to 2 June 2020, when the Italian government was applying the strictest lockdown on the entire population. Participation was asked through mailing lists, social media platforms (Facebook, Twitter, Instagram, WhatsApp), press releases, internet pages, television and radio news programmes, word of mouth and the study website (https:/ / epicovid19.itb.cnr.it/, accessed on 18 December 2021). Inclusion criteria were age $\geq 18$ years, access to a mobile phone, computer, or tablet with internet connectivity and provision of online consent to participate in the study. In total, 207,341 participants clicked on the first questionnaire link and 198,822 provided consent to participate and completed the first online survey. Participants who had consented to be contacted $(n=105,355,53 \%)$, by providing their personal email address during the first survey, received an email invitation (from 15 January to 28 February 2021) containing a personalized link that allowed them to complete the second questionnaire. In that period, the restrictions in Italy were less severe than during the first phase of the survey. Those who had not completed the EPICOVID19 phase II questionnaire within fifteen days since the invitation received up to three reminder emails. Exclusion of participants who did not receive the invitation or did not respond $(n=63,203)$, who did not provide consent $(n=653)$, and of those with inconsistencies in email contacts or who answered more than once using the same email address $(n=26)$ resulted in 41,473 respondents included in the present analysis (Figure 1). Excluded participants $(n=157,349)$ were younger, more likely residents in Southern regions or islands, with a lower educational level, and more frequently students (Table S3).

\subsection{Variables Collected and Data Transformations}

Variables of interest for the present study were the following: socio-demographic information (age, education, employment, job position at-risk for the infection, socio-economic status), body mass index (BMI, calculated as weight divided by height squared), number of chronic diseases (listed in Annex 1, question \#13), smoking habit, alcohol consumption, self-perceived health status [22] recoded as bad or very bad, adequate, and good or 
very good. Townsend Deprivation Scores (TDSs) was calculated as a proxy for individual level deprivation [23] by summing up, for each participant, the following variables (both dichotomized): unemployment, non-ownership of the house where he/she lives, no car owned by family members, and house crowding (defined as number of cohabitants greater than the number of rooms in the house, kitchen and bathrooms excluded). The total score ranged from 0 to 4 , with higher scores indicating higher deprivation. Sleep problems were measured using the Jenkins Sleep Scale (JSS) [24] based on four items. Each one was rated on a Likert-like scale from 0 to 5 , and the total score was the sum of all four items' scores and ranged from 0 (no sleep problems) to 20. The continuous score was dichotomized as follows: score lower than 12 showing a low frequency of sleep disturbances and score greater than 11 indicating high frequency of sleep disturbances) [25]. Personal stress was measured using the 10-item Perceived Stress Scale (PSS) [26] and adding five items developed ad hoc. Each item was rated on a Likert-like scale of 0 to 4 . The score was obtained firstly by reversing responses $(0=4,1=3,2=2,3=1$, and $4=0)$ to the four positively stated items (items 4, 5, 7, and 8) and then summing across all scale items. Individual scores fell in the range 0-40, higher scores indicating higher perceived stress. The score was categorized as follows: 0-13: low stress; 14-26: moderate stress; 27-40 high stress. Fear of contagion for oneself or relatives, fear about personal economic and job situation, and fear about the relatives' economic and job situation were assessed with a short questionnaire developed ad hoc for the present survey. Each aspect was rated on a Likert-like scale from 0 (no fear) to 4 , and the total score was the sum of all four items' scores and ranged from 0 to 16 , with higher scores indicating higher fear. Individual feelings about being sufficiently informed about COVID-19 was dichotomized into a binary variable.

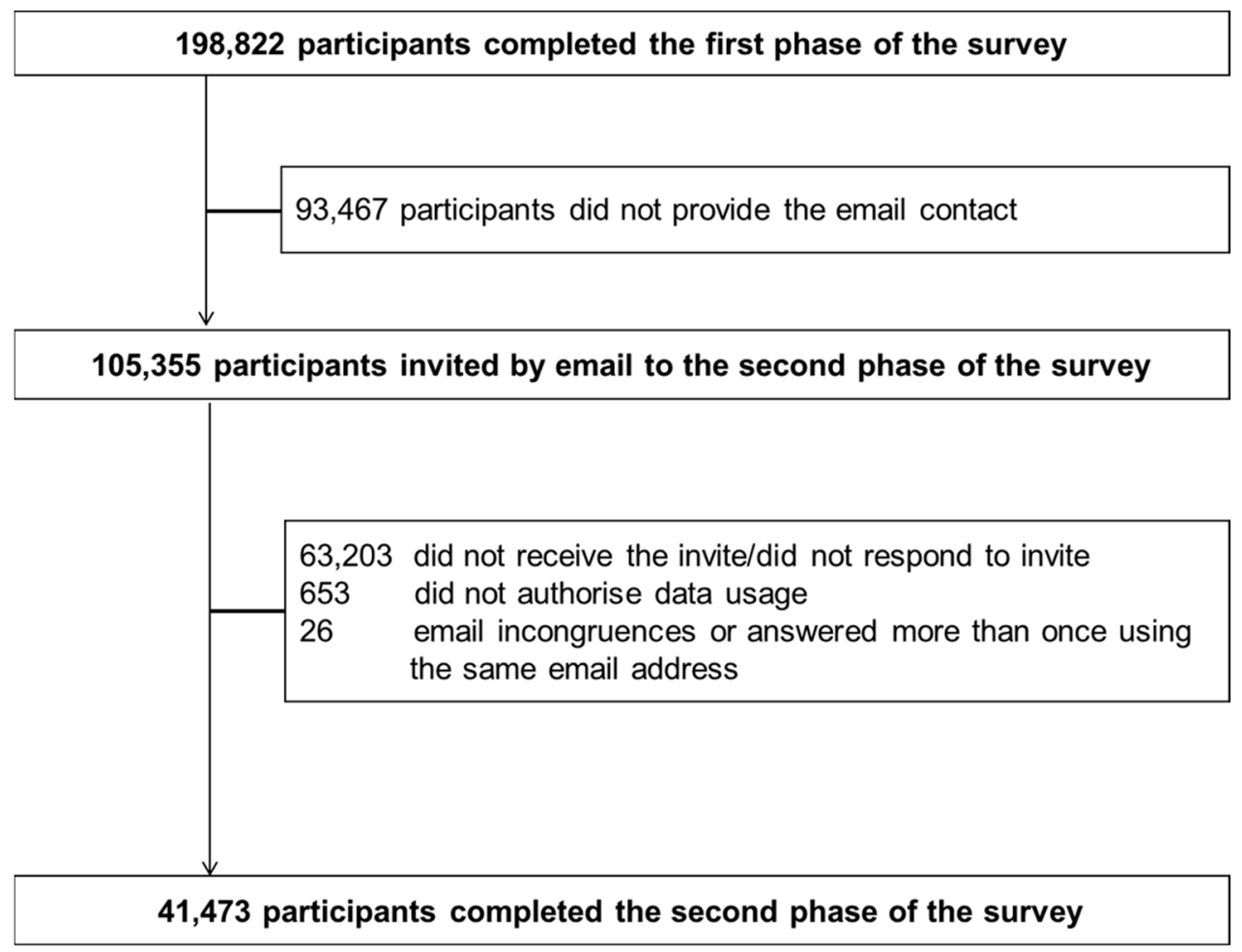

Figure 1. Flow-chart of the participants in phase II EPICOVID19 survey.

COVID-19-related variables have been reported including: contacts with COVID-19 cases, self-isolation, nasopharyngeal swab test (NPS) (numbers, results, reasons for having performed the positive test, places attended before the positive test), hospitalization, serological test (ST) (results, reasons for having performed the positive test), anti-COVID-19 vaccination(s), and SARS-CoV-2 infection-related symptoms. 


\subsection{Statistical Analysis}

The continuous variables were represented as mean and standard deviation (SD) and the categorical variables were expressed as numbers and percentages. The Student t-test and Chi-square test were used to compare the respondents' characteristics by sex for continuous and categorical variables, respectively. The threshold of statistical significance for any test was set at $p$-values of 0.05 . All of the statistical analyses were carried out using STATA software packages (version 15, StataCorp LP, 347 College Station, TX, USA) and SPSS (IBM Corp. Released, IBM SPSS Statistics version 25.0 Armonk, NY: IBM Corp.). The response rate map was drawn using the open-source data visualization Datawrapper $\mathrm{GmbH}$ tool (https: / / app.datawrapper.de/signin, accessed on 19 October 2021).

\subsection{Dissemination and Provision of Results to Participants}

The results of the first phase of the EPICOVID19 web-based survey were communicated mainly through peer-reviewed publications [14-21] in international scientific journals, meetings and conference presentations, workshops, the study website (www.epicovid1 9.itb.cnr.it, accessed on 18 December 2021), and disseminated through audio and video interviews and local printed media. A personalized e-mail with the provision of the results was sent to each participant who completed the survey and accepted to be contacted for communications about the project.

\section{Results}

The standardized response rates per 100,000 inhabitants by Italian regions over the January-February 2021 study period are represented in Figure 2 and Table S4. The percentages relating to the regional distribution of the Italian population were taken from the ISTAT website [27]. Darker coloured regions in Figure 2 indicate higher response rates which were mostly in northern Italy (Lombardia 137.5, Piemonte 106.6, Emilia-Romagna 100.6).

Table 1 summarizes the personal characteristics of the 41,473 participants who completed the phase II study according to sex. The mean age of the sample was 50.7 years \pm 13.5 SD (females $49.8 \pm 13.0$; males $52.2 \pm 14.3$ ) and $65.5 \%(n=27,158$ ) had a university degree or post-graduate qualification. Respondents were mostly employed with stable positions $(26,124,63 \%)$; during the emergency period, $44.5 \%(12,277)$ and $37.9 \%(10,458)$ continued to work on-site and alternated work from home and on-site work, respectively. Relatively to the risk of infection, the most represented job categories were school staff $(3653,13.2 \%)$ and the healthcare workers (3523, 12.8\%), with significant differences between males and females. A total of $0.6 \%$ had a high deprivation score (score $\geq 3$ ). The mean BMI was $24.4 \mathrm{~kg} / \mathrm{m}^{2} \pm 3.9 \mathrm{SD}$ (females $23.6 \pm 4.0$; males $25.6 \pm 3.5)$ and $4.9 \%(n=2044)$ of the whole sample reported three or more chronic diseases (5.2\% females; $4.9 \%$ males). A total of $57.7 \%(n=23,918)$ were never-smokers $(59.4 \%$ among females and 55.0\% among males) and 25,954 (62.6\%: 68.2\% females and 53.9\% males) were teetotalers or consumed alcoholic beverages between meals less than 5 times a month. A percentage of $8.1 \%$ reported sleep disorders during the previous month and $78.7 \%$ $(n=32,630)$ rated their own health status as good or very good $(77.4 \%$ females and $80.6 \%$ males). Most of the participants showed a low (50.9) or moderate (45.3) score at the PSS, with females having higher level of stress than males. More than $90 \%$ of the study participants felt they were sufficiently informed about the pandemic.

Table 2 reports COVID-19-related variables according to sex. Out of all the respondents, $70.6 \%(n=29,300)$ never had close contact with COVID-19 cases and have never been in self-isolation $(n=29,275)$. More than half of the respondents $(21,877,52.8 \%)$ underwent molecular NPS testing, and among them 2902 (13.2\%) tested positive at least once, with no differences between males (13.7\%) and females (13.0\%). One-fifth of tested participants performed more than four NPS during the study period and almost $90 \%$ underwent the molecular NPS test type instead of the rapid antigen-based test. The most frequent reason for the NPS testing with a positive result was the showing symptoms of COVID-19 (64.5\%), followed by having contact with a COVID-19 case $(44.2 \%) ; 41.3 \%$ referred to having shared 
the workplace within the 2 weeks before resulting positive to the NPS test. Among those who reported at least one positive NPS test, $359(12.4 \%)$ were hospitalized, more frequently males $(15.7 \%)$ than females $(10.2 \%)$. During the study period, $41.9 \%$ of the respondents $(n=17,394)$ underwent ST, and among them $2073(11.9 \%)$ tested positive at least once $(11.8 \%$ females and $12.2 \%$ males). Half of the participants performed the test because of their own choice $(49.9 \%)$. A total of $5.7 \%$ of the sample $(n=2371)$ received both doses of an anti-COVID-19 vaccine ( $6.5 \%$ females and $4.5 \%$ males).

The three most frequent self-referred symptoms (Figure 3, Table S5) in the whole sample were headache (27.9\%: $31.9 \%$ females and $21.6 \%$ males), sore throat/rhinorrhoea (24.5\%: $25.6 \%$ females and $22.4 \%$ males), and myalgia (21.9\%: $24.1 \%$ females and $18.4 \%$ males). Anosmia and dysgeusia were reported by $8.2 \%$ and $8.0 \%$ of the sample, and more frequently by females. Out of the 41,473 respondents of the second survey, 19,325 (46.6\%) reported no symptoms (50.6\% males and $44.0 \%$ females) (data not shown). On the other hand, among those with at least one positive NPS and/or ST $(n=4411)$, myalgia (64.6\%: $67.6 \%$ females and 59.7\% males), fever (58\%: 55.4\% females and $62.3 \%$ males), and headache (52.7\%: $58.1 \%$ females and $44 \%$ males) were the three most frequent self-reported symptoms. Anosmia and dysgeusia accounted for $51.6 \%$ (females $55.9 \%$ and males $44.7 \%$ ) and $48.3 \%$ (females $52.2 \%$ and males $42.0 \%$ ), respectively.

\section{Standardized response rates per 100,000 inhabitants (2021)}
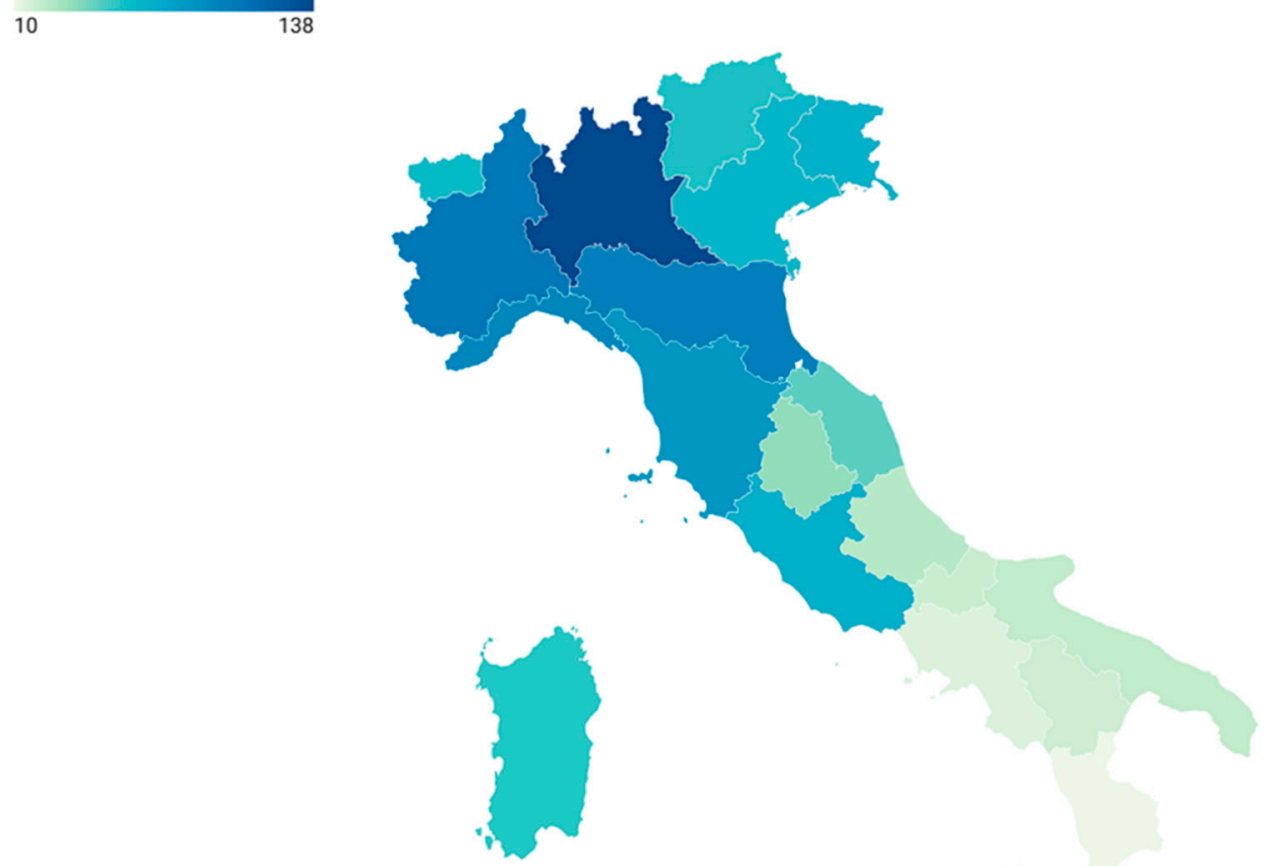

Figure 2. Response rates by Italian region in the phase II survey. Darker coloured regions indicate higher response rates. 
Table 1. Individual characteristics of the study participants by sex $(n=41,473)$.

\begin{tabular}{|c|c|c|c|c|}
\hline & & Sex at Birth & & \\
\hline & $\begin{array}{c}\text { Females } \\
n=25,146(60.6)\end{array}$ & $\begin{array}{c}\text { Males } \\
n=16,327(39.4)\end{array}$ & $p$-Value & $\begin{array}{c}\text { Total } \\
n=41,473(100)\end{array}$ \\
\hline & $n(\%)$ & $n(\%)$ & & $n(\%)$ \\
\hline Age $($ mean \pm SD) & $49.8 \pm 13.0$ & $52.2 \pm 14.3$ & 0.000 & $50.7 \pm 13.5$ \\
\hline 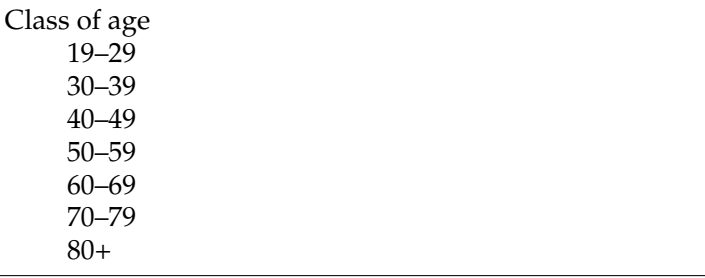 & $\begin{array}{c}1700(6.8) \\
4434(17.6) \\
5815(23.1) \\
6802(27.1) \\
5017(20.0) \\
1262(5.0) \\
116(0.5)\end{array}$ & $\begin{array}{c}1027(6.3) \\
2620(16.0) \\
3209(19.7) \\
3905(23.9) \\
3628(22.2) \\
1707(10.5) \\
231(1.4)\end{array}$ & 0.000 & $\begin{array}{c}2727(6.6) \\
7054(17.0) \\
9024(21.8) \\
10,707(25.8) \\
8645(20.8) \\
2969(7.2) \\
347(0.8) \\
\end{array}$ \\
\hline $\begin{array}{l}\text { Educational level }^{\text {a }} \\
\text { Low } \\
\text { Middle } \\
\text { High }\end{array}$ & $\begin{array}{c}723(2.9) \\
7286(29.0) \\
17,137(68.2)\end{array}$ & $\begin{array}{c}658(4.0) \\
5648(34.6) \\
10,021(61.4) \\
\end{array}$ & 0.000 & $\begin{array}{c}1381(3.3) \\
12,934(31.2) \\
27,158(65.5)\end{array}$ \\
\hline $\begin{array}{l}\text { Employment status } \\
\text { Employed, stable position } \\
\text { Employed, occasional worker } \\
\text { Temporary layoff } \\
\text { Unemployed, as before Jun } 2020 \\
\text { Unemployed, I lost my employment since Jun } 2020 \\
\text { Student } \\
\text { Retired } \\
\text { Other }\end{array}$ & $\begin{array}{c}15,676(62.3) \\
1056(4.2) \\
379(1.5) \\
1243(4.9) \\
446(1.8) \\
850(3.4) \\
3471(13.8) \\
2025(8.1) \\
\end{array}$ & $\begin{array}{c}10,448(64.0) \\
407(2.5) \\
114(0.7) \\
271(1.7) \\
193(1.2) \\
583(3.6) \\
3420(20.9) \\
891(5.5)\end{array}$ & 0.000 & $\begin{array}{c}26,124(63.0) \\
1463(3.5) \\
493(1.2) \\
1514(3.7) \\
639(1.5) \\
1433(3.5) \\
6891(16.6) \\
2916(7.0) \\
\end{array}$ \\
\hline $\begin{array}{l}\text { Working at } \\
\text { Workplace } \\
\text { Home and workplace } \\
\text { Home }\end{array}$ & $\begin{array}{l}7798(46.6) \\
6188(37.0) \\
2746(16.4)\end{array}$ & $\begin{array}{l}4479(41.3) \\
4270(39.3) \\
2106(19.4)\end{array}$ & 0.000 & $\begin{array}{c}12,277(44.5) \\
10,458(37.9) \\
4852(17.6)\end{array}$ \\
\hline $\begin{array}{l}\text { Work category at risk for the infection } \\
\text { No } \\
\text { Personnel who work indoors with high turnout } \\
\text { School staff } \\
\text { Healthcare workers } \\
\text { Other (armed forces, haidressers, pilots, etc) }\end{array}$ & $\begin{array}{l}10,242(61.2) \\
896(5.4) \\
2880(17.2) \\
2572(15.4) \\
142(0.8)\end{array}$ & $\begin{array}{c}8331(76.7) \\
477(4.4) \\
773(7.1) \\
951(8.8) \\
323(3.0)\end{array}$ & 0.000 & $\begin{array}{c}18,573(67.3) \\
1373(5.0) \\
3653(13.2) \\
3523(12.8) \\
465(1.7)\end{array}$ \\
\hline $\begin{array}{l}\text { Deprivation Score }{ }^{b} \\
\text { Zero } \\
\text { One } \\
\text { Two } \\
\text { Three } \\
\text { Four }\end{array}$ & $\begin{array}{l}15,005(59.7) \\
8248(32.8) \\
1704(6.8) \\
182(0.7) \\
7(0.0)\end{array}$ & $\begin{array}{c}10,368(63.5) \\
4995(30.6) \\
893(5.5) \\
68(0.4) \\
3(0.0)\end{array}$ & 0.000 & $\begin{array}{c}25,373(61.2) \\
13,243(31.9) \\
2597(6.3) \\
250(0.6) \\
10(0.0)\end{array}$ \\
\hline Body Mass Index & $23.6 \pm 4.0$ & $25.6 \pm 3.5$ & 0.000 & $24.4 \pm 3.9$ \\
\hline $\begin{array}{l}\mathrm{N}^{\circ} \text { of morbidities } \\
\text { None } \\
\text { One } \\
\text { Two } \\
\text { Three or more }\end{array}$ & $\begin{array}{c}15,369(61.1) \\
6042(24.0) \\
2416(9.6) \\
1319(5.2)\end{array}$ & $\begin{array}{c}10,660(65.3) \\
3553(21.8) \\
1389(8.5) \\
725(4.4)\end{array}$ & 0.000 & $\begin{array}{c}26,029(62.8) \\
9595(23.1) \\
3805(9.2) \\
2044(4.9) \\
\end{array}$ \\
\hline $\begin{array}{l}\text { Smoking habit } \\
\text { No } \\
\text { Former smoker } \\
\text { Current smoker }\end{array}$ & $\begin{array}{c}14,939(59.4) \\
5538(22.0) \\
4669(18.6)\end{array}$ & $\begin{array}{l}8979(55.0) \\
4545(27.8) \\
2803(17.2)\end{array}$ & 0.000 & $\begin{array}{c}23,918(57.7) \\
10,083(24.3) \\
7472(18.0)\end{array}$ \\
\hline $\begin{array}{l}\text { Frequency of alcohol beverages between meals } \\
\text { Never } \\
<5 \text { times a month } \\
2-3 \text { times a week } \\
4-5 \text { times a week } \\
6+\text { times a week }\end{array}$ & $\begin{array}{c}5739(22.8) \\
11,409(45.4) \\
4240(16.9) \\
2033(8.1) \\
1725(6.9)\end{array}$ & $\begin{array}{l}2043(12.5) \\
6763(41.4) \\
3337(20.4) \\
1794(11.0) \\
2390(14.6)\end{array}$ & 0.000 & $\begin{array}{c}7782(18.8) \\
18,172(43.8) \\
7577(18.3) \\
3827(9.2) \\
4115(9.9)\end{array}$ \\
\hline $\begin{array}{l}\text { Self-perceived health status } \\
\text { Bad or very bad } \\
\text { Adequate } \\
\text { Good or very good }\end{array}$ & $\begin{array}{c}4181.7) \\
5263(20.9) \\
19,465(77.4)\end{array}$ & $\begin{array}{c}221(1.4) \\
2941(18.0) \\
13,165(80.6)\end{array}$ & 0.000 & $\begin{array}{c}639(1.5) \\
8204(19.8) \\
32,630(78.7)\end{array}$ \\
\hline
\end{tabular}


Table 1. Cont.

\begin{tabular}{|c|c|c|c|c|}
\hline & \multicolumn{3}{|c|}{ Sex at Birth } & \multirow[b]{2}{*}{$\begin{array}{c}\text { Total } \\
n=41,473(100)\end{array}$} \\
\hline & $\begin{array}{c}\text { Females } \\
n=25,146(60.6)\end{array}$ & $\begin{array}{c}\text { Males } \\
n=16,327(39.4)\end{array}$ & $p$-Value & \\
\hline & $n(\%)$ & $n(\%)$ & & $n(\%)$ \\
\hline Sleep problems ${ }^{c}$ & $2509(10.0)$ & $850(5.2)$ & 0.000 & $3359(8.1)$ \\
\hline Perceived stress ${ }^{\mathrm{d}}$ & & & 0.000 & \\
\hline Low & $10,748(44.1)$ & 9550 (61.5) & & $20,298(50.9)$ \\
\hline Moderate & $12,445(51.1)$ & $5633(36.3)$ & & $18,078(45.3)$ \\
\hline High & $1168(4.8)$ & $343(2.2)$ & & $1511(3.8)$ \\
\hline Fear about COVID-19 pandemic (mean \pm SD) ${ }^{\mathrm{e}}$ & $8.6 \pm 3.6$ & $7.9 \pm 3.5$ & 0.000 & $8.4 \pm 3.6$ \\
\hline Feeling to be sufficiently informed about COVID-19 & $23,443(93.2)$ & $15,200(93.1)$ & 0.607 & $38,643(93.2)$ \\
\hline
\end{tabular}

Table 2. COVID-19-related variables by sex $(n=41,473)$.

\begin{tabular}{|c|c|c|c|c|}
\hline & \multicolumn{3}{|c|}{ Sex at Birth } & \multirow[b]{2}{*}{$\begin{array}{c}\text { Total } \\
n=41,473(100)\end{array}$} \\
\hline & $\begin{array}{c}\text { Females } \\
n=25,146(60.6)\end{array}$ & $\begin{array}{c}\text { Males } \\
n=16,327(39.4)\end{array}$ & $p$-Value & \\
\hline & $n(\%)$ & $n(\%)$ & & $n(\%)$ \\
\hline Close contact with COVID-19 cases & & & 0.000 & \\
\hline No & $17,356(69.0)$ & $11,944(73.2)$ & & $29,300(70.6)$ \\
\hline Yes, wearing a face mask & $4630(18.4)$ & $2504(15.3)$ & & $7134(17.2)$ \\
\hline Yes, at least once without wearing a face mask & $3160(12.6)$ & $1879(11.5)$ & & $5039(12.2)$ \\
\hline Quarantine or self-isolation & & & 0.000 & \\
\hline Never & $17,441(69.4)$ & $11,834(72.5)$ & & $29,275(70.6)$ \\
\hline Once & $6500(25.8)$ & $3768(23.1)$ & & $10,268(24.8)$ \\
\hline More than once & $1205(4.8)$ & $725(4.4)$ & & $1930(4.7)$ \\
\hline NPS test for SARS-CoV-2 ${ }^{\wedge} *$ & & & 0.000 & \\
\hline Not done & $11,592(46.1)$ & $8004(49.0)$ & & $19,596(47.3)$ \\
\hline Yes, always negative & $11,792(46.9)$ & $7183(44.0)$ & & $18,975(45.8)$ \\
\hline Yes, positive at least once & $1762(7.0)$ & $1140(7.0)$ & & $2902(7.0)$ \\
\hline If tested, number of NPS & & & 0.071 & \\
\hline 1 & $5715(42.2)$ & $3615(43.4)$ & & $9330(42.6)$ \\
\hline 2 & $3129(23.1)$ & $1948(23.4)$ & & $5077(23.2)$ \\
\hline 3 & $1902(14.0)$ & $1148(13.8)$ & & $3050(13.9)$ \\
\hline $4+$ & $2808(20.7)$ & $1612(19.4)$ & & $4420(20.2)$ \\
\hline Molecular NPS test type & $1590(90.2)$ & $995(87.3)$ & 0.030 & $2585(89.1)$ \\
\hline NPS test performed for free & 1405 (79.7) & $870(76.3)$ & 0.029 & $2275(78.4)$ \\
\hline \multicolumn{5}{|l|}{ Reasons for the positive NPS test performed } \\
\hline Presence of symptoms & $1124(63.8)$ & $748(65.6)$ & 0.316 & $1872(64.5)$ \\
\hline Contact with COVID-19 case & $827(46.9)$ & $455(39.9)$ & 0.000 & $1282(44.2)$ \\
\hline Check at workplace & 205 (11.6) & $93(8.2)$ & 0.003 & $298(10.3)$ \\
\hline Own choice & $79(4.5)$ & $77(6.8)$ & 0.008 & $156(5.4)$ \\
\hline Other reasons & $86(4.9)$ & $69(6.1)$ & 0.170 & $155(5.3)$ \\
\hline \multicolumn{5}{|l|}{ Places attended two weeks before the positive NPS test } \\
\hline School & $215(12.2)$ & $54(4.7)$ & 0.000 & $269(9.3)$ \\
\hline Bar/restaurants & $408(23.2)$ & $373(32.7)$ & 0.000 & $781(26.9)$ \\
\hline Gym/swimming pool/club/discotheques & $125(7.1)$ & $84(7.4)$ & 0.780 & $209(7.2)$ \\
\hline Churches & $175(9.9)$ & $98(8.6)$ & 0.229 & $273(9.4)$ \\
\hline
\end{tabular}


Table 2. Cont.

\begin{tabular}{|c|c|c|c|c|}
\hline & \multicolumn{3}{|c|}{ Sex at Birth } & \multirow[b]{2}{*}{$\begin{array}{c}\text { Total } \\
n=41,473(100)\end{array}$} \\
\hline & $\begin{aligned} & \text { Females } \\
n= & 25,146(60.6)\end{aligned}$ & $\begin{array}{c}\text { Males } \\
n=16,327(39.4)\end{array}$ & $p$-Value & \\
\hline & $n(\%)$ & $n(\%)$ & & $n(\%)$ \\
\hline Hairdresser/aesthetic centre & $223(12.7)$ & $45(3.9)$ & 0.000 & $268(9.2)$ \\
\hline Theatres/cinemas/museum & $35(2.0)$ & $23(2.0)$ & 0.953 & $58(2.0)$ \\
\hline Parties (friends, family) & $298(16.9)$ & $241(21.1)$ & 0.004 & $539(18.6)$ \\
\hline Public transports $>3$ times/week & $132(7.5)$ & $82(7.2)$ & 0.764 & $214(7.4)$ \\
\hline Shared workplace & $759(43.1)$ & $440(38.6)$ & 0.017 & 1199 (41.3) \\
\hline Hospitalization after NPS positive test & $180(10.2)$ & $179(15.7)$ & 0.000 & $359(12.4)$ \\
\hline ST for SARS-CoV-2 ** & & & 0.000 & \\
\hline Not done & $14,054(55.9)$ & $10,025(61.4)$ & & $24,079(58.1)$ \\
\hline Yes, always negative & $9788(38.9)$ & $5533(33.9)$ & & $15,321(36.9)$ \\
\hline Yes, positive at least once & $1304(5.2)$ & $769(4.7)$ & & $2073(5.0)$ \\
\hline \multicolumn{5}{|l|}{ Reasons for the positive ST performed } \\
\hline Check at workplace & $450(34.5)$ & $188(24.4)$ & 0.000 & $638(30.8)$ \\
\hline Own choice & $594(45.6)$ & $440(57.2)$ & 0.000 & $1034(49.9)$ \\
\hline Other reasons & $311(23.8)$ & $168(21.8)$ & 0.296 & $479(23.1)$ \\
\hline Vaccinated for COVID-19 at 2nd interview & & & 0.000 & \\
\hline No & $21,967(87.4)$ & $14,853(91.0)$ & & $36,820(88.8)$ \\
\hline Yes, only the first dose & $1540(6.1)$ & $742(4.5)$ & & $2282(5.5)$ \\
\hline Yes, both doses & $1639(6.5)$ & $732(4.5)$ & & $2371(5.7)$ \\
\hline
\end{tabular}

* NPS: nasopharyngeal swab; ${ }^{\wedge}$ SARS-CoV-2: severe acute respiratory syndrome coronavirus $2 ;{ }^{* *}$ ST: serological test.

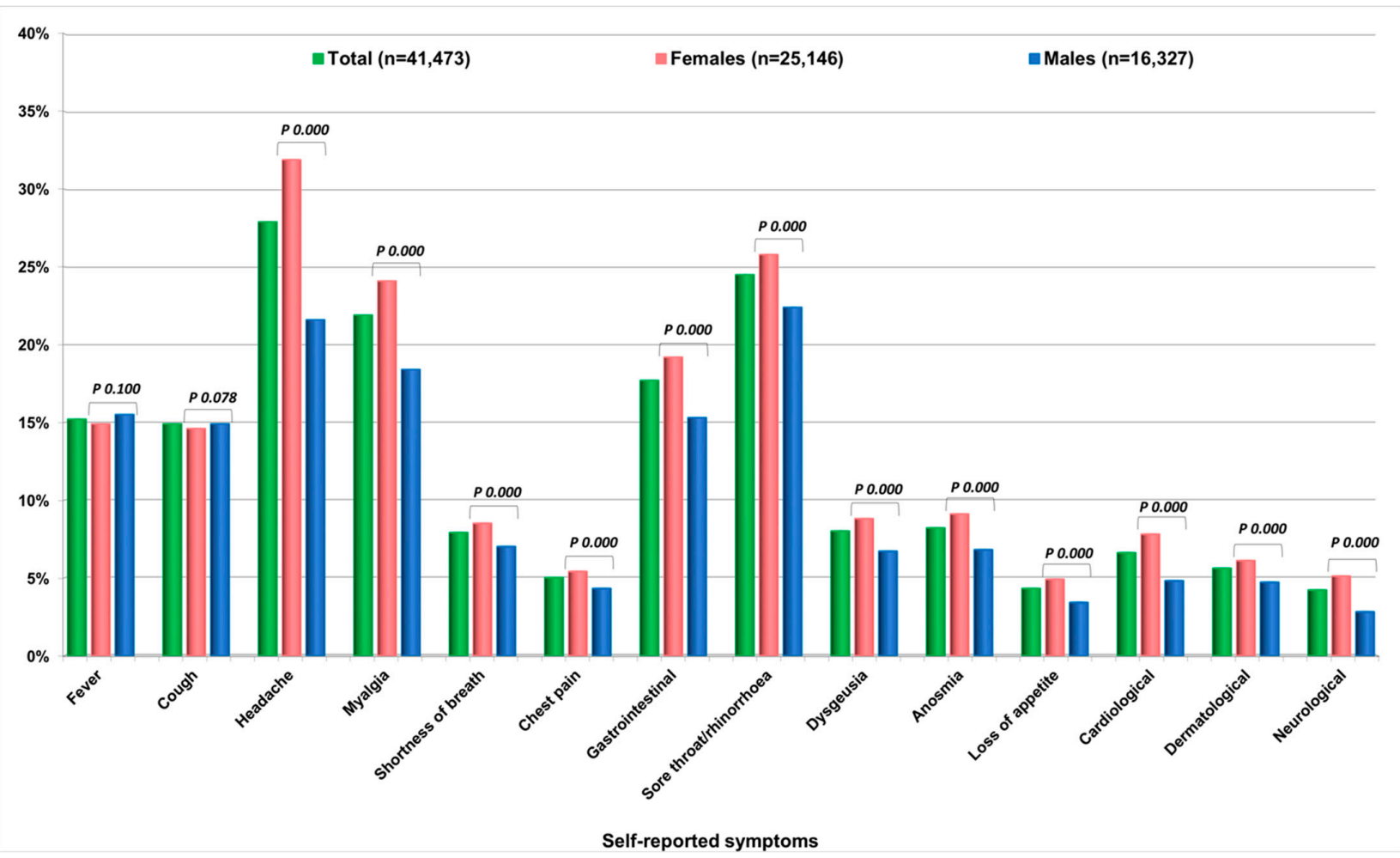

Figure 3. Frequency of self-reported symptoms by sex between March 2020 and February 2021 $(n=41,473)$ and $p$-values of the comparisons between females and males.

During the period March 2020-February 2021, 33.3\% ( $n=13,805)$ did not perform any COVID-19 tests, $24.8 \%(n=10,274)$ underwent NPS only, $14.0 \%(n=5791)$ underwent 
ST only, whereas $28.0 \%(n=11,603)$ performed both NPS and ST (data not shown). Out of the 2073 participants with at least one positive ST, $1509(72.8 \%)$ had undergone one or more NPS always with negative results or never performed it. In the group of participants diagnosed (NPS or ST) with SARS-CoV-2 infection $(n=4411)$, more than one-third (Figure 4$)$ was aware that they had the infection, which was not intercepted in its acute phase (NPS never executed or executed with negative result, before or after known seropositivity), with slight differences between sexes.

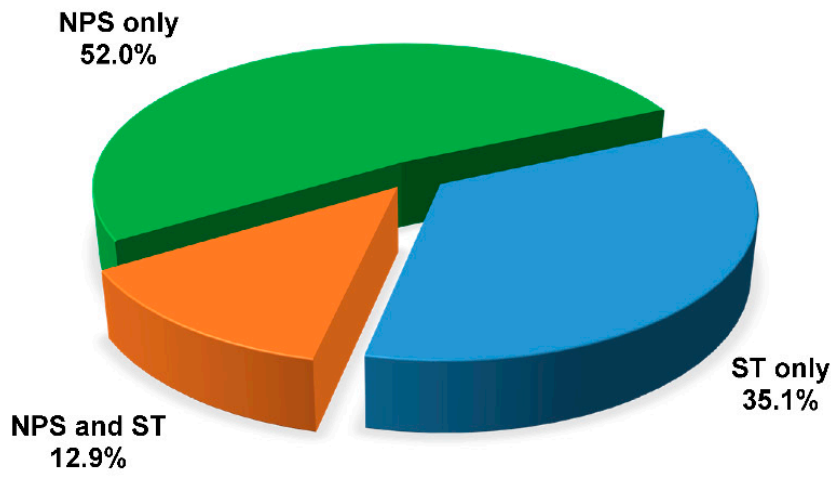

Females, $n=2716$

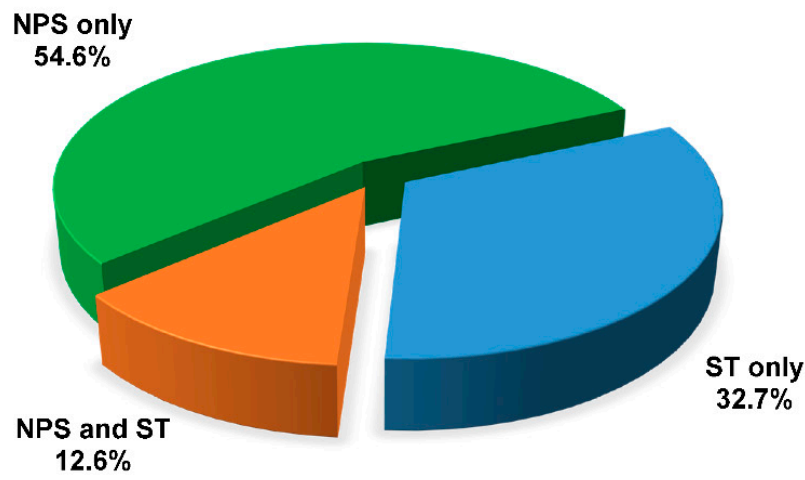

Males, $n=1695$

Figure 4. Distribution of positivity to SARS-CoV-2 by type of test performed in 4411 cases between March 2020 and February 2021 by sex. NPS: nasopharyngeal swab. ST: serological test.

\section{Discussion}

This article provides a snapshot of the socio-demographic and clinical characteristics of the 41,473 respondents who participated in the second phase of the web-based EPICOVID19 study conducted in Italy during January-February 2021. It also shows the frequency of the NPS and/or ST tests, the prevalence of positivity to SARS-CoV-2 among the tested participants, and the frequency of COVID-19 related symptoms in a median study period of ten months since March 2020.

The EPICOVID19 questionnaires had the power to collect some data useful to characterize the individual behaviours of the respondents involving several aspects of daily life usually not collected in clinical context. The national coverage of the survey was in line with the geographical spread of COVID-19 during the first wave [2], when participants were recruited. As for work conditions, the majority of the participants (63\%) maintained their stable work position with $18 \%$ shifting to work from home, the data in accordance with the Eurostat Statistics. In 2020, 12.3\% of employed aged 15-64 years said they often work in agile mode in the European Union, and an identical percentage was reported in Italy (12.2\%) [28]. Furthermore, according to the Smart Working Observatory of the Politecnico di Milano [29], during the lockdown about 6.6 million workers shifted to remote working. Among the work category at high risk of infection, school staff and healthcare workers represent almost $30 \%$ of the study sample, with a significant unbalance toward the female sex, as expected.

Regarding the perception of health status and mood disorders, $78.7 \%$ referred to perceive a good or very good health status with no substantial difference between females and males. However, $8.1 \%$ and $49.1 \%$ reported sleep disorders and moderate-to-high selfperceived stress during the month before the survey completion, respectively. Similar to these findings, recent studies reported a high prevalence of sleep problems [30] and a high level of stress or anxiety [31] during the COVID-19 outbreak. The results of the present study also showed that females are more likely to manifest sleep disorders and psychological stress as pointed out in other investigations [32,33]. Furthermore, females are more worried about contagion for themselves or relatives and about personal and relatives' economic and job situation, confirming the results of phase I of the EPICOVID19 survey [20]. These 
data reinforce indications that, although males are at higher risk of developing a severe infection than females [34], the latter are more concerned about COVID-19. This could reflect a stronger adherence to virtuous behaviours in females compared to males [35].

Considering the COVID-19-related variables, during the second survey, fever, headache, myalgia, and olfactory and taste disorders were the most frequent self-reported symptoms among those who tested positive, which are consistently reported as peculiar symptoms associated with SARS-CoV-2 infection $[13,14,36]$. More than half of the sample underwent the NPS test (positive rate of $13.2 \%$ ), because of suspected symptoms or contact with a COVID-19 case. More than 40\% referred to having shared the workplace in the two weeks before having been tested. About $40 \%$ of the sample performed an ST, mostly voluntarily, and $11.9 \%$ resulted positive. Taken together, these percentages are significantly higher compared to the official number of positive cases officially reported in Italy for the period March 2020-February 2021 ( $n=2,925,265$ cases in 59,641,488 residents) [2,27], confirming the potential large underestimation of the actual number of exposed or infected. Ideally, only by combining large seroprevalence epidemiological studies (screening tool) with massive NPS testing (diagnostic tool) this issue could be addressed. Most recent Italian serosurveillances still report a very broad range of prevalence estimates. Vena et al. [37] reported $11 \% \mathrm{IgG}$ and/or IgM positivity in a large adult Italian population between March and April 2020. Among the volunteers recruited in the Marche region from March to June 2020, the authors found a seroprevalence of $14.4 \%$, without significant differences between sex and age groups [38]. As of June 2020, in a population-based study [39] carried out in a northern municipality that was heavily affected by SARS-CoV-2 infection, authors found an overall positivity to SARS-CoV-2 of $22.6 \%$, varying according to age groups. On the other side, the Italian National Institute of Statistics (ISTAT) estimated a much lower seroprevalence of $2.5 \%$ in a large sample from 2000 Italian municipalities during the summer of 2020 [40]. Looking at other countries, a systematic review and meta-analysis that included 47 studies involving 399,265 people from 23 countries up to 14 August 2020, reported a seroprevalence that varied from $0.37 \%$ to $22.1 \%$ in the general population. Limiting the analysis to the Italian dataset, the authors reported a pooled seroprevalence of 7.27 (95\%CI 2.48-11.9) and an estimated number of people infected by SARS-CoV-2 of 4,395,587 (95\%CI $1,499,457-7,249,393)[41]$.

Our large-scale data showed no sex difference in the proportion of respondents infected with SARS-CoV-2, in accordance with current knowledge. Although epidemiological evidence in the early phase of pandemic suggested that males had higher risk of SARS-CoV2 infection than females [42], subsequent evidence demonstrated that this risk difference was not significant [43]. This indicates that unequal access to healthcare and testing between sexes could have skewed towards a male bias in diagnosing the infection during the first wave of the pandemic. On the other hand, males were more frequently hospitalized and possibly manifested a more severe disease than females in the present sample. This is consistent with the large body of literature reporting that males face higher rates of hospitalization, intensive therapy unit admission, and death compared to females [34]. We also observed specific sex-differences in relation to the self-reported COVID-19-like symptoms, in which females tend to systematically over-report symptoms. Because no sex difference in the rate of positivity to the diagnostic or screening test has been observed, a possible explanation might reside in the fact that females were more worried about the health situation and tended to be more prone to the phenomenon of the 'nocebo effects' compared to males, as shown in other studies [44-46]. In line with available evidence, considering only participants with positive results from NPS and/or ST, males more often reported symptoms, such as fever and cough, known as predictors of worse outcomes [47], whereas females reported more frequently symptoms susceptible to subjective perception (headache, anosmia, dysgeusia, sore throat) and generally associated with less severe infections [48,49].

Females also completed more frequently an anti-COVID-19 vaccination cycle compared to their male counterparts. The sex unbalance can be explained by the fact that 
among the healthcare workers (representing $80 \%$ of those who received both vaccine doses in our sample), 73\% were females (data in line with the other European Member States [50]). These results reflect the effects of the Guidelines on the Strategic Plan for COVID-19 Vaccines released on 2 December 2020, by the Ministry of Health. These Guidelines, in fact, recommended starting the vaccination campaign by first selecting specific categories, such as healthcare social workers, residents and staff working in nursing homes, at high risk of infection or of spreading the virus [51]. The low percentage of vaccinated $(5.7 \%)$ in our sample was expected as the anti-COVID-19 vaccination campaign started the beginning of January 2021 in Italy, when the survey presented in this manuscript was carried out (15 January-28 February).

Remarkably, out of the 2073 participants with at least one positive ST during the period March 2020-February 2021, 72.8\% underwent one or more NPS always with negative results or never performed it. Among those with COVID-19, more than one-third became aware that they contracted the infection without being tested (or having a negative result at the NPS), meaning that a considerable number of undiagnosed cases escaped the detection from surveillance systems and was not officially certified as positive. COVID-19 has caught most countries unprepared and has highlighted the unreadiness of health systems [52]. In particular, during the first wave of the pandemic, most countries encountered difficulties in carrying out diagnostic tests, thus limiting the effectiveness of testing, tracking, and contact tracing [5]. Consequently, the number of SARS-CoV-2 infections in the asymptomatic or subclinical infected individuals was largely undetected [53], thus leading to a considerable underestimation of the number of actual cases [54,55].

This large fraction of people, who had not undergone self-isolation or quarantine, is likely to have contributed to the transmission of SARS-CoV-2 infection and to the spread of the disease outbreaks in small communities such as households [56] during the most severe restrictions period, or such as workplaces [57] when the restrictions were less stringent.

The whole body of the data collected and results described in this manuscript will allow us to investigate a number of interesting topics. Among these, we will focus on the association of behavioural factors or individual characteristics with the infection in the two phases of the study; on the impact of pandemics on stress, sleep, and other lifestyles; and on the hesitancy towards an anti-COVID19 vaccination. We plan to address each of these topics with specific methodologies, which are beyond the scope of this descriptive manuscript, in future publications.

\section{Limitations and Strengths}

This present study has some weaknesses, primarily because the online system and voluntary participation suffers from inherent selection bias and generalizability. Similar to other web-based surveys [8,58,59], some of the characteristics of the sample were not adequately representative of the Italian adult population. Indeed, females, younger, healthier, and wealthier people were more represented in the enrolled sample with respect to the general population. Further, data were self-reported, which might have introduced measurement and recall bias (e.g., survey question misunderstanding, etc.). In addition, the longitudinal design may have led to bias due to the loss of participants during the follow-up period. The response rate to the second survey was $40 \%$, with some differences between included and excluded participants, in particular regarding age, education, employment status, and geographical area of residence.

The present study also has several strengths, including its community-based longitudinal design with two time-point's measures overlapping with the first and second wave of the epidemic in Italy, thus providing reliable details on the temporal evolution of the symptoms and testing. In addition, although these data were self-reported, almost 50\% of the studied sample underwent an NPS or ST, providing an overarching picture of the positivity rate at the population level in a country in which the ability to track COVID-19 cases in real time was limited. The exhaustive data collection on socio-demographic, medical, behavioural, and psychological factors, as well as the large sample size, is a further 
strength of this study. Lastly, the EPICOVID19 web survey has reached a large sample of adults covering all Italian regions, although the response rate was unbalanced in favour of the northern regions, being the Italian geographical area more dramatically affected by the first wave of the pandemic at the time of enrolment.

\section{Conclusions}

EPICOVID19 is the largest web-based survey released when the first two waves of COVID-19 outbreak occurred in Italy. It offers a unique opportunity to estimate the number of individuals asymptomatic or mild symptomatic at the community level, to explore the factors associated with the SARS-CoV-2 infection, and to evaluate the consequences on health and wellbeing of the COVID-19 pandemic in Italy. The descriptive results of the phase II of the EPICOVID19 survey indicate that the positivity rate among Italian adults in February 2021 varied from $11.9 \%$ (ST) to 13.2\% (NPS). Furthermore, the study highlights that a relevant fraction of positive cases remained uncertified from the official statistics, which possibly may have contributed to the spread of the virus in the community.

Complementary to the activities of testing and contact tracing, the adoption of participatory online surveys for collecting epidemiological data on a multidimensional scale should be considered strategic to support decision makers in planning evidence-based public health actions to control the spread of SARS-CoV-2 infection.

Supplementary Materials: The following supporting information can be downloaded at: https: / / www.mdpi.com/article/10.3390/ijerph19031274/s1, Annex 1: Phase II EPICOVID19 questionnaire; Table S1: Contents of the web-based questionnaires; Table S2: Validated scales and questionnaires used in EPICOVID19 survey; Table S3: Characteristics of individuals who participated in phase II survey and of those who did not; Table S4: Standardized response rates per 100,000 inhabitants by Italian region over the phase II study period; Table S5: Frequency of self-reported symptoms by sex and by positivity to NPS and/or ST between March 2020 and February 2021. Membership of the EPICOVID19 Working Group.

Author Contributions: Conceptualization, F.A., F.B., R.A.-I., S.M., M.G. and F.P.; Data curation, F.A., N.J., E.P., A.S. and F.P.; Formal analysis, F.A.; Investigation, F.A. and F.P.; Methodology, F.A., A.G., M.N., C.T., L.C. and F.P.; Project administration, F.A. and F.P.; Resources, N.J., E.P., A.S. and EPICOVID19 Working Group; Supervision, F.P.; Writing-original draft preparation, F.A. and F.P.; Writing-review and editing, N.J., E.P., A.S., A.G., M.N., C.T., M.F., S.P., L.C., C.M.M., F.B., R.A.-I., S.M. and M.G. All authors have read and agreed to the published version of the manuscript.

Funding: This research received no external funding.

Institutional Review Board Statement: The study was conducted in accordance with the Declaration of Helsinki, and approved by the Ethics Committee of the Istituto Nazionale per le Malattie Infettive IRCCS Lazzaro Spallanzani (protocol No. 70, 12 April 2020 and protocol No. 249, 14 January 2021). Data were handled and stored following the European Union General Data Protection Regulation (EU-GDPR) 2016/679, and housed in the ITB-CNR server in Italy. Data transfer was safeguarded by encrypting and decrypting data and password protection.

Informed Consent Statement: When participants first accessed the web-based platform, they were informed about the study and its purpose, the data to be collected, and the methods of storage; they then filled out the informed consent form. Participants were able to start the EPICOVID19 questionnaire only after consenting. Participation was voluntary and no compensation was given to respondents.

Data Availability Statement: Data are available on request.

Acknowledgments: The authors would like to thank all the participants who took part in this study and made it possible, and all the collaborators of the EPICOVID19 Working Group (in alphabetical order by last name): Adorni Fulvio, National Research Council, Institute of Biomedical Technologies, Epidemiology Unit, Segrate (MI), Italy; Andreoni Massimo, Infectious Diseases Clinic, Department of System Medicine, Tor Vergata University of Rome, Rome, Italy; Antonelli Incalzi Raffaele, Unit of Geriatrics, Department of Medicine, Biomedical Campus of Rome, Rome, Italy; Bastiani Luca, National Research Council, Institute of Clinical Physiology, Pisa (PI), Italy; Bianchi Fabrizio, National 


\begin{abstract}
Research Council, Institute of Clinical Physiology, Pisa (PI), Italy; Di Bari Mauro, Geriatric Intensive Care Medicine, University of Florence and Azienda Ospedaliero-Universitaria Careggi, Florence, Italy; Fortunato Loredana, National Research Council, Institute of Clinical Physiology, Pisa (PI), Italy; Galli Massimo, Infectious Diseases Unit, Department of Biomedical and Clinical Sciences L Sacco, Università di Milano, ASST Fatebenefratelli Sacco, Milan, Italy; Giacomelli Andrea, Infectious Diseases Unit, Department of Biomedical and Clinical Sciences L Sacco, Università di Milano, ASST Fatebenefratelli Sacco, Milan, Italy; Jesuthasan Nithiya, National Research Council, Institute of Biomedical Technologies, Epidemiology Unit, Segrate (MI), Italy; Maggi Stefania, National Research Council, Neuroscience Institute, Aging Branch, Padova, Italy; Mastroianni Claudio, Public Health and Infectious Disease Department, Sapienza University, Rome, Italy; Molinaro Sabrina, National Research Council, Institute of Clinical Physiology, Pisa (PI), Italy; Noale Marianna, National Research Council, Neuroscience Institute, Aging Branch, Padova, Italy; Pagani Gabriele, Infectious Diseases Unit, Department of Biomedical and Clinical Sciences L Sacco, Università di Milano, ASST Fatebenefratelli Sacco, Milan, Italy; Pedone Claudio, Unit of Geriatrics, Department of Medicine, Biomedical Campus of Rome, Rome, Italy; Pettenati Carla, National Research Council, Institute of Biomedical Technologies, Segrate (MI), Italy; Prinelli Federica, National Research Council, Institute of Biomedical Technologies, Epidemiology Unit, Segrate (MI), Italy; Rusconi Stefano, Infectious Diseases Unit, Department of Biomedical and Clinical Sciences L Sacco, Università di Milano, ASST Fatebenefratelli Sacco, Milan, Italy; Sojic Aleksandra, National Research Council, Institute of Biomedical Technologies, Epidemiology Unit, Segrate (MI), Italy; Tavio Marcello, Division of Infectious Diseases, Azienda Ospedaliero Universitaria Ospedali Riuniti, Torrette, Ancona, Italy; and Trevisan Caterina, Geriatric Unit, Department of Medicine (DIMED), University of Padova, Padova, Italy, and National Research Council, Neuroscience Institute, Aging Branch, Padova, Italy.
\end{abstract}

Conflicts of Interest: The authors declare no conflict of interest.

\title{
References
}

1. European Centre for Disease Prevention and Control. Available online: https://www.ecdc.europa.eu/en/publications-data/ rapid-risk-assessment-resurgence-reported-cases-covid-19 (accessed on 18 December 2021).

2. Arcgis COVID-19 Situazione Italia. Available online: http://opendatadpc.maps.arcgis.com/apps/opsdashboard/index.html\# /b0c68bce2cce478eaac82fe38d4138b1 (accessed on 20 December 2021).

3. Russell, T.W.; Golding, N.; Hellewell, J.; Abbott, S.; Wright, L.; Pearson, C.A.; van Zandvoort, K.; Jarvis, C.I.; Gibbs, H.; Liu, Y.; et al. Reconstructing the early global dynamics of under-ascertained COVID-19 cases and infections. BMC Med. 2020, 18, 1-9. [CrossRef] [PubMed]

4. Pullano, G.; Di Domenico, L.; Sabbatini, C.E.; Valdano, E.; Turbelin, C.; Debin, M.; Guerrisi, C.; Kengne-Kuetche, C.; Souty, C.; Hanslik, T.; et al. Underdetection of cases of COVID-19 in France threatens epidemic control. Nature 2021, 590, 134-139. [CrossRef] [PubMed]

5. Yang, J.; Chen, X.; Deng, X.; Chen, Z.; Gong, H.; Yan, H.; Wu, Q.; Shi, H.; Lai, S.; Ajelli, M.; et al. Disease burden and clinical severity of the first pandemic wave of COVID-19 in Wuhan, China. Nat. Commun. 2020, 11, 5411. [CrossRef] [PubMed]

6. Budd, J.; Miller, B.S.; Manning, E.M.; Lampos, V.; Zhuang, M.; Edelstein, M.; Rees, G.; Emery, V.C.; Stevens, M.M.; Keegan, N.; et al. Digital technologies in the public-health response. Nat. Med. 2020, 26, 1183-1192. [CrossRef]

7. McCall, B. COVID-19 and artificial intelligence: Protecting health-care workers and curbing the spread. Lancet Digit. Health 2020, 2, e166-e167. [CrossRef]

8. Menni, C.; Valdes, A.M.; Freidin, M.B.; Sudre, C.H.; Nguyen, L.H.; Drew, D.A.; Ganesh, S.; Varsavsky, T.; Cardoso, M.J.; Moustafa, J.S.E.-S.; et al. Real-time tracking of self-reported symptoms to predict potential COVID-19. Nat. Med. 2020, 26, 1037-1040. [CrossRef]

9. Robertson, M.M.; Kulkarni, S.G.; Rane, M.; Kochhar, S.; Berry, A.; Chang, M.; Mirzayi, C.; You, W.; Maroko, A.; Zimba, R.; et al. Cohort profile: A national, community-based prospective cohort study of SARS-CoV-2 pandemic outcomes in the USA-the CHASING COVID Cohort study. BMJ Open 2021, 11, e048778. [CrossRef]

10. Rossman, H.; Keshet, A.; Shilo, S.; Gavrieli, A.; Bauman, T.; Cohen, O.; Shelly, E.; Balicer, R.; Geiger, B.; Dor, Y.; et al. A framework for identifying regional outbreak and spread of COVID-19 from one-minute population-wide surveys. Nat. Med. 2020, 26, 634-638. [CrossRef]

11. Krausz, M.; Westenberg, J.N.; Vigo, D.; Spence, R.T.; Ramsey, D. Emergency Response to COVID-19 in Canada: Platform Development and Implementation for eHealth in Crisis Management. JMIR Public Health Surveill. 2020, 6, e18995. [CrossRef]

12. Wu, D.C.; Jha, P.; Lam, T.; Brown, P.; Gelband, H.; Nagelkerke, N.; Birnboim, H.C.; Reid, A.; Action to Beat Coronavirus in Canada/Action pour Battre le Coronavirus (Ab-C) Study Group. Predictors of self-reported symptoms and testing for COVID-19 in Canada using a nationally representative survey. PLoS ONE 2020, 15, e0240778. [CrossRef] 
13. Sudre, C.H.; Keshet, A.; Graham, M.S.; Joshi, A.D.; Shilo, S.; Rossman, H.; Murray, B.; Molteni, E.; Klaser, K.; Canas, L.D.; et al. Anosmia, ageusia, and other COVID-19-like symptoms in association with a positive SARS-CoV-2 test, across six national digital surveillance platforms: An observational study. Lancet Digit. Health 2021, 3, e577-e586. [CrossRef]

14. Adorni, F.; Prinelli, F.; Bianchi, F.; Giacomelli, A.; Pagani, G.; Bernacchia, D.; Rusconi, S.; Maggi, S.; Trevisan, C.; Noale, M.; et al. Self-Reported Symptoms of SARS-CoV-2 Infection in a Nonhospitalized Population in Italy: Cross-Sectional Study of the EPICOVID19 Web-Based Survey. JMIR Public Health Surveill. 2020, 6, e21866. [CrossRef] [PubMed]

15. Bastiani, L.; Fortunato, L.; Pieroni, S.; Bianchi, F.; Adorni, F.; Prinelli, F.; Giacomelli, A.; Pagani, G.; Maggi, S.; Trevisan, C.; et al. Rapid COVID-19 Screening Based on Self-Reported Symptoms: Psychometric Assessment and Validation of the EPICOVID19 Short Diagnostic Scale. J. Med. Internet Res. 2021, 23, e23897. [CrossRef]

16. Trevisan, C.; Noale, M.; Prinelli, F.; Maggi, S.; Sojic, A.; Di Bari, M.; Molinaro, S.; Bastiani, L.; Giacomelli, A.; Galli, M.; et al. Age-Related Changes in Clinical Presentation of Covid-19: The EPICOVID19 Web-Based Survey. J. Med. Internet Res. 2021, 23, e23897. [CrossRef]

17. Prinelli, F.; Bianchi, F.; Drago, G.; Ruggieri, S.; Sojic, A.; Jesuthasan, N.; Molinaro, S.; Bastiani, L.; Maggi, S.; Noale, M.; et al. Association Between Smoking and SARS-CoV-2 Infection: Cross-sectional Study of the EPICOVID19 Internet-Based Survey. JMIR Public Health Surveill. 2021, 7, e27091. [CrossRef]

18. Noale, M.; Trevisan, C.; Maggi, S.; Antonelli Incalzi, R.; Pedone, C.; Di Bari, M.; Adorni, F.; Jesuthasan, N.; Sojic, A.; Galli, M.; et al. The Association between Influenza and Pneumococcal Vaccinations and SARS-Cov-2 Infection: Data from the EPICOVID19 Web-Based Survey. Vaccines 2020, 8, 471. [CrossRef]

19. Giacomelli, A.; Galli, M.; Maggi, S.; Pagani, G.; Incalzi, R.A.; Pedone, C.; Di Bari, M.; Noale, M.; Trevisan, C.; Bianchi, F.; et al. Missed Opportunities of Flu Vaccination in Italian Target Categories: Insights from the Online EPICOVID 19 Survey. Vaccines 2020, 8, 669. [CrossRef]

20. Cori, L.; Curzio, O.; Adorni, F.; Prinelli, F.; Noale, M.; Trevisan, C.; Fortunato, L.; Giacomelli, A.; Bianchi, F. Fear of COVID-19 for Individuals and Family Members: Indications from the National Cross-Sectional Study of the EPICOVID19 Web-Based Survey. Int. J. Environ. Res. Public Health 2021, 18, 3248. [CrossRef]

21. Trevisan, C.; Pedone, C.; Maggi, S.; Noale, M.; Di Bari, M.; Sojic, A.; Molinaro, S.; Giacomelli, A.; Bianchi, F.; Tavio, M.; et al. Accessibility to SARS-CoV-2 swab test during the Covid-19 pandemic: Did age make the difference? Health Policy 2021, 125, 1580-1586. [CrossRef]

22. Eurostat. Available online: https://ec.europa.eu/eurostat/statistics-explained/index.php?title=Glossary:Self-perceived_health (accessed on 18 December 2021).

23. Townsend, P.; Phillimore, P.; Beattie, A. Health and Deprivation. Inequality and the North; Croom Helm Ltd.: London, UK, 1987; p. 221, ISBN 0-7099-4352-0.

24. Jenkins, C.D.; Stanton, B.A.; Niemcryk, S.J.; Rose, R.M. A scale for the estimation of sleep problems in clinical research. J. Clin. Epidemiol. 1988, 41, 313-321. [CrossRef]

25. Monterrosa-Castro, Á.; Portela-Buelvas, K.; Salguedo-Madrid, M.; Mo-Carrascal, J.; Leidy, C.D.-M. Instruments to study sleep disorders in climacteric women. Sleep Sci. 2016, 9, 169-178. [CrossRef] [PubMed]

26. Cohen, S.; Kamarck, T.; Mermelstein, R. A global measure of perceived stress. J. Health Soc. Behav. 1983, 24, 385-396. [CrossRef] [PubMed]

27. I.Stat. Available online: http:/ / dati.istat.it/ (accessed on 15 November 2021).

28. Eurostat. Available online: https:/ / ec.europa.eu/eurostat/web/products-eurostat-news/-/edn-20210517-2 (accessed on 18 December 2021).

29. Osservatori.net. Digital Innovation. Available online: https://www.osservatori.net/it/ricerche/comunicati-stampa/smartworking-emergenza-covid19-new-normal (accessed on 18 December 2021).

30. Alimoradi, Z.; Broström, A.; Tsang, H.W.H.; Griffiths, M.D.; Haghayegh, S.; Ohayon, M.M.; Lin, C.Y.; Pakpour, A.H. Sleep problems during COVID-19 pandemic and its' association to psychological distress: A systematic review and meta-analysis. EClinicalMedicine 2021, 36, 100916. [CrossRef] [PubMed]

31. Lin, L.Y.; Wang, J.; Ou-Yang, X.Y.; Miao, Q.; Chen, R.; Liang, F.-X.; Zhang, Y.-P.; Tang, Q.; Wang, T. The immediate impact of the 2019 novel coronavirus (COVID-19) outbreak on subjective sleep status. Sleep Med. 2021, 77, 348-354. [CrossRef]

32. García-Fernández, L.; Romero-Ferreiro, V.; Padilla, S.; David, L.P.; Monzó-García, M.; Rodriguez-Jimenez, R. Gender differences in emotional response to the COVID-19 outbreak in Spain. Brain Behav. 2021, 11, e01934. [CrossRef]

33. Guadagni, V.; Umilta, A.; Iaria, G. Sleep Quality, Empathy, and Mood During the Isolation Period of the COVID-19 Pandemic in the Canadian Population: Females and Women Suffered the Most. Front. Glob. Women's Health 2020, 1, 585938. [CrossRef]

34. Peckham, H.; de Gruijter, N.M.; Raine, C.; Radziszewska, A.; Ciurtin, C.; Wedderburn, L.R.; Rosser, E.C.; Webb, K.; Deakin, C.T. Male sex identified by global COVID-19 meta-analysis as a risk factor for death and ITU admission. Nat. Commun. 2020, 11, 6317. [CrossRef]

35. Galasso, V.; Pons, V.; Profeta, P.; Becher, M.; Brouard, S.; Foucault, M. Gender differences in COVID-19 attitudes and behavior: Panel evidence from eight countries. Proc. Natl. Acad. Sci. USA 2020, 117, 27285-27291. [CrossRef]

36. Giacomelli, A.; Pezzati, L.; Conti, F.; Bernacchia, D.; Siano, M.; Oreni, L.; Rusconi, S.; Gervasoni, C.; Ridolfo, A.L.; Rizzardini, G.; et al. Self-reported Olfactory and Taste Disorders in Patients With Severe Acute Respiratory Coronavirus 2 Infection: A Cross-sectional Study. Clin. Infect. Dis. 2020, 71, 889-890. [CrossRef] 
37. Vena, A.; Berruti, M.; Adessi, A.; Blumetti, P.; Brignole, M.; Colognato, R.; Gaggioli, G.; Giacobbe, D.R.; Bracci-Laudiero, L.; Magnasco, L.; et al. Prevalence of Antibodies to SARS-CoV-2 in Italian Adults and Associated Risk Factors. J. Clin. Med. 2020, 9, 2780. [CrossRef]

38. De Santi, M.; Diotallevi, A.; Brandi, G. Seroprevalence of Severe Acute Respiratory Syndrome Coronavirus-2 (SARS-CoV-2) infection in an Italian cohort in Marche Region, Italy. Acta Biomed. 2021, 92, e2021070. [CrossRef] [PubMed]

39. Pagani, G.; Conti, F.; Giacomelli, A.; Bernacchia, D.; Rondanin, R.; Prina, A.; Scolari, V.; Gandolfi, C.E.; Castaldi, S.; Marano, G.; et al. Seroprevalence of SARS-CoV-2 significantly varies with age: Preliminary results from a mass population screening. J. Infect. 2020, 81, e10-e12. [CrossRef] [PubMed]

40. Ministero della Salute. Available online: http://www.salute.gov.it/imgs/C_17_notizie_4998_0_file.pdf (accessed on 18 December 2021).

41. Rostami, A.; Sepidarkish, M.; Leeflang, M.M.G.; Riahi, S.M.; Shiadeh, M.N.; Esfandyari, S.; Mokdad, A.H.; Hotez, P.J.; Gasser, R.B. SARS-CoV-2 seroprevalence worldwide: A systematic review and meta-analysis. Clin. Microbiol. Infect. 2021, 27, 331-340. [CrossRef] [PubMed]

42. Abate, B.B.; Kassie, A.M.; Kassaw, M.W.; Aragie, T.G.; Masresha, S.A. Sex difference in coronavirus disease (COVID-19): A systematic review and meta-analysis. BMJ Open 2020, 10, e040129. [CrossRef]

43. The Sex, Gender and COVID-19 Project, Men, Sex Gender and COVID-19. Available online: https://globalhealth5050.org/thesex-gender-and-covid-19-project/ (accessed on 18 December 2021).

44. Daniali, H.; Flaten, M.A. What Psychological Factors Make Individuals Believe They Are Infected by Coronavirus 2019? Front. Psychol. 2021, 12, 667722. [CrossRef]

45. Daniali, H.; Flaten, M.A. Experiencing COVID-19 symptoms without the disease: The role of nocebo in reporting of symptoms. Scand. J. Public Health 2021. [CrossRef]

46. Aslaksen, P.M.; Myrbakk, I.N.; Høifødt, R.S.; Flaten, M.A. The effect of experimenter gender on autonomic and subjective responses to pain stimuli. Pain 2007, 129, 260-268. [CrossRef]

47. Biolè, C.; Bianco, M.; Núñez-Gil, I.J.; Cerrato, E.; Spirito, A.; Roubin, S.R.; Viana-Llamas, M.C.; Gonzalez, A.; Castro-Mejia, A.F.; Eid, C.M.; et al. Gender Differences in the Presentation and Outcomes of Hospitalized Patients With COVID-19. J. Hosp. Med. 2021, 16, 349-352. [CrossRef]

48. Lechien, J.R.; Chiesa-Estomba, C.M.; Place, S.; Van Laethem, Y.; Cabaraux, P.; Mat, Q.; Huet, K.; Plzak, J.; Horoi, M.; Hans, S.; et al. Clinical and epidemiological characteristics of 1420 European patients with mild-to-moderate coronavirus disease 2019. J. Intern. Med. 2020, 288, 335-344. [CrossRef]

49. Ancochea, J.; Izquierdo, J.L.; Soriano, J.B. Evidence of Gender Differences in the Diagnosis and Management of Coronavirus Disease 2019 Patients: An Analysis of Electronic Health Records Using Natural Language Processing and Machine Learning. J. Women's Health 2021, 30, 393-404. [CrossRef]

50. Eurostat. Available online: https:/ / ec.europa.eu/eurostat/web/products-eurostat-news/-/DDN-20200409-2 (accessed on 18 December 2021).

51. Ministero della Salute. Available online: https://www.salute.gov.it/portale/news/p3_2_1_1_1.jsp?lingua=italiano\&menu= notizie\& $\mathrm{p}=$ dalministero\&id $=5208$ (accessed on 18 December 2021).

52. World Health Organization. Available online: https://www.who.int/publications/i/item/WHO-UHL-PHC-SP-2021.02 (accessed on 18 December 2021).

53. Oran, D.P.; Topol, E.J. The Proportion of SARS-CoV-2 Infections That Are Asymptomatic: A Systematic Review. Ann. Intern. Med. 2021, 174, 655-662. [CrossRef] [PubMed]

54. Stringhini, S.; Wisniak, A.; Piumatti, G.; Azman, A.S.; Lauer, S.A.; Baysson, H.; De Ridder, D.; Petrovic, D.; Schrempft, S.; Marcus, K.; et al. Seroprevalence of anti-SARS-CoV-2 IgG antibodies in Geneva, Switzerland (SEROCoV-POP): A population-based study. Lancet 2020, 396, 313-319. [CrossRef]

55. Pollán, M.; Pérez-Gómez, B.; Pastor-Barriuso, R.; Oteo, J.; Hernán, M.A.; Pérez-Olmeda, M.; Sanmartín, J.L.; Fernández-García, A.; Cruz, I.; de Larrea, N.F.; et al. Prevalence of SARS-CoV-2 in Spain (ENE-COVID): A nationwide, population-based seroepidemiological study. Lancet 2020, 396, 535-544. [CrossRef]

56. Madewell, Z.J.; Yang, Y.; Longini, I.M.; Halloran, M.E.; Dean, N.E. Household Transmission of SARS-CoV-2: A Systematic Review and Meta-analysis. JAMA Netw. Open 2020, 3, e2031756. [CrossRef] [PubMed]

57. Daniels, S.; Wei, H.; Han, Y.; Catt, H.; Denning, D.W.; Hall, I.; Regan, M.; Verma, A.; Whitfield, C.A.; van Tongeren, M. Risk factors associated with respiratory infectious disease-related presenteeism: A rapid review. BMC Public Health 2021, 21, 1955. [CrossRef] [PubMed]

58. Drew, D.A.; Nguyen, L.H.; Steves, C.J.; Menni, C.; Freydin, M.; Varsavsky, T.; Sudre, C.H.; Cardoso, M.J.; Ourselin, S.; Wolf, J.; et al. Rapid implementation of mobile technology for real-time epidemiology of COVID-19. Science 2020, 368, 1362-1367. [CrossRef]

59. Astley, C.M.; Tuli, G.; Mc Cord, K.A.; Cohn, E.L.; Rader, B.; Varrelman, T.J.; Chiu, S.L.; Deng, X.; Stewart, K.; Farag, T.H.; et al. Global monitoring of the impact of the COVID-19 pandemic through online surveys sampled from the Facebook user base. Proc. Natl. Acad. Sci. USA 2021, 118, e2111455118. [CrossRef] 
Reproduced with permission of copyright owner. Further reproduction prohibited without permission. 